\title{
Parameters Identification of Moving Load Using ANN and Dynamic Strain
}

\author{
Hui Yang, ${ }^{1}$ Weiming Yan, ${ }^{1,2}$ and Haoxiang $\mathrm{He}^{1,2}$ \\ ${ }^{1}$ Beijing Key Laboratory of Earthquake Engineering and Structural Retrofit, Beijing University of Technology, \\ Beijing 100124, China \\ ${ }^{2}$ Beijing Collaborative Innovation Center for Metropolitan Transportation, Beijing 100124, China \\ Correspondence should be addressed to Haoxiang He; hhx7856@163.com
}

Received 25 December 2015; Accepted 2 March 2016

Academic Editor: Rafał Burdzik

Copyright (C) 2016 Hui Yang et al. This is an open access article distributed under the Creative Commons Attribution License, which permits unrestricted use, distribution, and reproduction in any medium, provided the original work is properly cited.

\begin{abstract}
Moving load identification is an important part of bridge structure health monitoring; accurate and reliable load data can be used to check the load of bridge design, and the load spectrum can provide a more practical basis for structural fatigue analysis. The method of the BP neural network is used in bridge moving loads identification. The numerical examples of identification of the axle loads of a two-axle vehicle moving on a simply supported bridge under various speeds and weights are carried out. The sensitivity of the bridge deflection and strain to moving loads is analyzed, and the influences of different activation function combinations and algorithm on network are discussed. The identification results of different load conditions are analyzed and the effect of noise is considered. Finally the rationality of the method is verified by experiments. It is shown that the indirect estimation of vehicle weight by BP neural network from dynamic responses is feasible.
\end{abstract}

\section{Introduction}

With the quick development of transportation and infrastructure, bridge plays an important role and becomes a key part of the lifeline. In recent decades, all kinds of bridges have been built worldwide, such as highway bridge, railway bridge, both railway and highway bridges, and city crossroad. From construction to operation, bridge is subjected to different types of loads, such as environmental loads and vehicle loads. The vibration of bridge can be easily generated when various vehicles travel across the deck. Continual operation traffic loads over time can lead to fatigue and deterioration of bridge structures. The axle loads and gross weight of vehicles are important information for bridge design, fatigue life assessments of existing bridges, design code calibration, and control of overweight vehicles to highway regulations. Therefore, it is necessary to obtain accurate axle loads of moving vehicles on the bridge. The measurement technology of dynamic vehicle has been developed for many years, and the most widely used device is the Weight-in-Motion system. Weightin-Motion system is a set of sensors and a set of electronic devices containing software to measure the weight of the vehicle. It can be divided into different categories according to different sensors. At present, there are three types of sensors in Weight-in-Motion system, which are strain gauge sensor, capacitive sensor, and piezoelectric transducer. The Weightin-Motion system based on the resistance strain gauge has the advantages of fast measurement, high sensitivity, reliable performance, and stability, but the maintenance is huge and expensive and needs digging up the road surface when installing, and this will cause some damage to the structure. The Weight-in-Motion system based on the capacitive sensor has high sensitivity and can obtain the large amount of variation with high signal-to-noise ratio with system stability. It has a simple structure and can work in extreme temperature or other rigorous environments. The disadvantage is that the electromagnetic interference is obvious and the filling medium in capacitors is easy to deform. Besides, it needs to be checked regularly. The Weight-in-Motion system based on the piezoelectric transducer is the main research direction in the field of dynamic weighing. Piezoelectric transducer is a kind of capacitive sensor, but compared with the general capacitive sensor, its size is smaller and easier to install. 
Compared to the strain sensor, the construction difficulty of the piezoelectric transducer is smaller, the service life is longer, and the economic cost is lower [1]. Although the Weight-in-Motion system has developed rapidly, it still has many shortcomings. For example, the currently widely used Weight-in-Motion system is weak in high-speed detection, sensitivity, and accuracy and needs to excavate the deck during installation, and they all can only measure the static axle loads. In fact, the dynamic effects of the moving vehicle cause much larger bridge responses, especially when unfavorable road roughness exists, which will increase the average surface damage about two to four times compared to that from the static axle forces [2]. Therefore, it is necessary to identify the dynamic force between the vehicle and bridge. With the bridge accidents having increased year after year, the government and the engineer are paying more attention to the monitoring for bridge and more bridge monitoring systems have been successively established. Monitoring the dynamic response of the bridge is one of the important contents in the health monitoring system. The normal monitoring system of bridge will produce important information every day. Using these data for moving load identification can not only achieve the purpose of monitoring the running state of the bridge, but also identify the vehicle load without increasing cost, which has important significance.

Axle loads identification methods based on the inverse problem of decomposing the dynamic bridge response to vehicle axle loads have been studied and developed for many years. At present, the methods that are used commonly include time domain method, frequency-time domain method, finite element method, and fitting method. The time domain approach models the structure and forces with a set of second-order differential equations. The forces are modeled as step functions in a small time interval. These equations of motion are then expressed in the modal coordinates, and they are solved by convolution in the time domain. The forces are then identified using the modal superposition principle [3]. Frequency-time domain method performed the Fourier transformation on the equation of motion that was expressed in modal coordinates. The relation between the responses and the forces was obtained in the frequency domain. The time histories of the forces were found by the least-squares method [4]. In the finite element method, the measured displacements are expressed as the shape functions of the finite elements of the structure which is modeled as a straight beam. The measured responses can be limited to a small number of master degrees of freedom of the structural system. This avoids the usual modal coordinate transformation and the errors accompanied with the modal truncation in the dynamic responses [5]. In the fitting method, the vibration response of the beam is fitted with select function, and their derivatives are obtained by means of spline numerical differentiation. Then the regularized solution is obtained by using Tikhonov regularization and singular values decomposition $[6,7]$. All of these methods have promoted the development of moving loads identification of bridge. But because of the complexity of bridge moving loads identification, each method has its merits, limitations, and disadvantages. Such results from all the above methods exhibit large fluctuations in the identified force time histories, and they are highly sensitive to the noise level in the measured responses. They need to be improved and enhanced for practical application in field tests.

The problem of identifying parameters of vehicles traveling on bridges is actually an inverse optimization problem. As an inverse problem of structural mechanics, force identification is difficult to solve the differential equations of motion of the system directly. In order to solve this bottleneck problem, more suitable tools are needed. Artificial neural network (ANN) is a functional abstraction of the biologic neural structures of the central nervous system [8]. ANN has the powerful ability of pattern reorganization and classification. ANN operates as a black box, model-free, and adaptive tool to capture and learn significant structures in data. The computing abilities of ANN have been proven in the fields of prediction and estimation, pattern recognition, and optimization [9-12]. ANN is suitable particularly for problems that are too complex to be modeled and solved by classical mathematics and traditional procedures. In the past two decades, artificial neural networks have experienced significant developments in the domain of the inverse. ANN has opened up new possibilities for diverse fields such as damage detection of bridges [13-16] and structures [17-21], smart structures [22], and model updating of structural systems $[23,24]$. As a very important innovation in ANN, BP neural network is the abbreviation of erroneous reverse transmission neural network, which is presently one of the most successful and widely applied neural network models. And its strong ability of logical reasoning makes it particularly suitable for solving the problems like damage identification and load identification [25]. However, if the neural network is applied to moving load identification, the input and output of the network should be determined and network structure (e.g., number of hidden neurons or kernels), activation function and algorithm, and so forth should be established also, since these parameters have important influence on the performance of the network. How to establish a suitable neural network model and use the proposed model for moving load identification is the focus of the neural network method in loads identification.

In this paper, the BP neural network method is applied to identify the moving loads. The sensitivity of input and output is analyzed, and the influence of different activation function combinations and algorithms on loads identification accuracy is studied. It is considered that the BP neural network method is feasible for moving loads identification, which can be used to identify the location, speed, and dynamic loads of the vehicle under the action of moving loads.

\section{Dynamic Response of Bridge under Moving Loads and Its Sensitivity}

In this study, the dynamic loads on the bridge are identified by dynamic responses, and the responses of the bridge under the action of moving loads are analyzed. A time-varying force is moving on a simply supported Euler-Bernoulli beam, as shown in Figure 1. The size of the cross section and the 


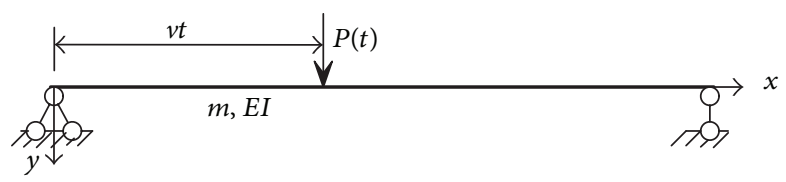

FIGURE 1: Simply supported beam subjected to a moving force.

mass per unit length are both constants, and the bridge has viscous proportional damping and only elastic small deflections occur [26]. The bridge length is $L$, and the force $P(t)$ moves from the left side to the right side in a constant speed $v$. The dynamic equation can be written as

$$
\begin{aligned}
& m \frac{\partial^{2} u(x, t)}{\partial t^{2}}+c \frac{\partial u(x, t)}{\partial t}+E I \frac{\partial^{4} u(x, t)}{\partial x^{4}} \\
& \quad=\delta(x-v t) P(t)
\end{aligned}
$$

The beam deflection response under moving force can be obtained by solving (1) as

$$
\begin{aligned}
& u(x, t)=\frac{2}{m L} \sum_{n=1}^{\infty} \frac{1}{\omega_{D n}} \sin \frac{n \pi x}{L} \\
& \cdot \int_{0}^{t} P(\tau) \sin \frac{n \pi v \tau}{L} e^{-\xi_{n} \omega_{n}(t-\tau)} \sin \omega_{D n}(t-\tau) d \tau,
\end{aligned}
$$

where $m$ is the mass per unit length, $u(x, t)$ is the beam deflection at point $x$ and time point $t, c$ is the viscous damping parameter, $E I$ is the constant flexural stiffness, $\delta(x)$ is the Dirac delta function, $\omega_{D n}$ is the $n$th damping modal frequency, $\omega_{n}$ is the $n$th nondamping modal frequency, and $\xi_{n}$ is the damping ratio of the $n$th mode.

For the beam section with bending deformation, the strain $\varepsilon(x, t)$ in the beam bottom can be calculated according to deflection response $u(x, t)$; that is,

$$
\varepsilon(x, t)=\frac{y_{h}}{\rho(x, t)}=y_{h} \frac{d^{2} u(x, t) / d x^{2}}{\sqrt{\left[1+(d u(x, t) / d x)^{2}\right]^{3}}} .
$$

For the small deformation of the beam, omitting the small senior items in (3), we have

$$
\varepsilon(x, t)=\frac{y_{h}}{\rho(x, t)}=y_{h} \frac{d^{2} u(x, t)}{d x^{2}},
$$

where $y_{h}$ is the distance between the bottom surface and the flexural neutral surface of the beam and $\rho(x, t)$ is the curvature radius of the beam at point $x$ and time $t$.

It can be seen from (4) that the strain is closely related to the second derivative of the vertical deflection of the beam. Therefore, the strain of the main section of the beam under moving load contains a wealth of information about high-frequency components, and it can intensively represent the deformation characteristics of the structure. If the noise interference is ignored, the dynamic strain implies the parameter information of the load more comprehensively than the deflection; thus, the strain responses can be collected and analyzed in the actual moving load identification.

In order to verify the above viewpoint, the dynamic response of a simply supported beam under moving load is simulated by finite element software ANSYS; then the deflection and the strain of the main section are analyzed. The parameters of the simply supported beam are as follows: the length of the beam $L$ is $30 \mathrm{~m}$, the elastic modulus $E$ is $3.25 \times$ $10^{10} \mathrm{~N} / \mathrm{m}^{2}$, the moment of inertia $I$ is $0.76923 \mathrm{~m}^{4}$, the crosssectional area $S$ is $1.923 \mathrm{~m}^{2}$, and the density $\rho$ is $2600 \mathrm{~kg} / \mathrm{m}^{2}$. The beam body is divided into 300 elements. The sampling frequency is $100 \mathrm{~Hz}$. It is assumed that 7 displacement gauges and 7 strain gauges are installed evenly on the bottom of beam along the $x$-axes, and the corresponding deflection and strain responses are stored and analyzed, and the simulated moving load is $392 \mathrm{kN}$ and $794 \mathrm{kN}$, respectively, and the speed is $20 \mathrm{~m} / \mathrm{s}$.

The deflection and strain responses of different locations are shown in Figures 2 and 3, respectively. It can be seen that the deflections and strains of the beam are affected not only by the load value but also by the load location; the deflections and the strains will increase when the load moves more close to the measurement point or sensor. Meanwhile, the overall sensitivity of deflection and strain to load value is similar, but the strain is more sensitive to load location. Therefore, the dynamic strain of beam is selected as the major signal in the parameter identification of moving loads.

\section{Identification of Moving Loads Using BP Neural Network}

Structural dynamic load can be solved by the dynamic characteristics of the structure and the measured dynamic response, which belongs to the second type of inverse problems in structural dynamics [27]. Due to the diversity of the bridge structure and the loads diversity and uncertainty of the distribution in time and space domain, the moving load identification for vehicle-bridge system model is hard to be solved if it is viewed as a mathematical inversion process, and there exist model errors and ill posed problems. Artificial neural network has strong nonlinear mapping ability and adaptive learning ability. It is unnecessary to establish a complex mathematical model for neural network; highly nonlinear mapping can be realized from $R^{n}$ ( $n$ is the input node number) space to $R^{m}$ ( $m$ is the output node number) space [28], which is very suitable for solving the problem of moving loads identification. Using neural network to identify the moving load, in fact, is to find the intrinsic link between the parameters of the moving loads and the responses of the bridge. It is just like a problem that predicts or estimates 


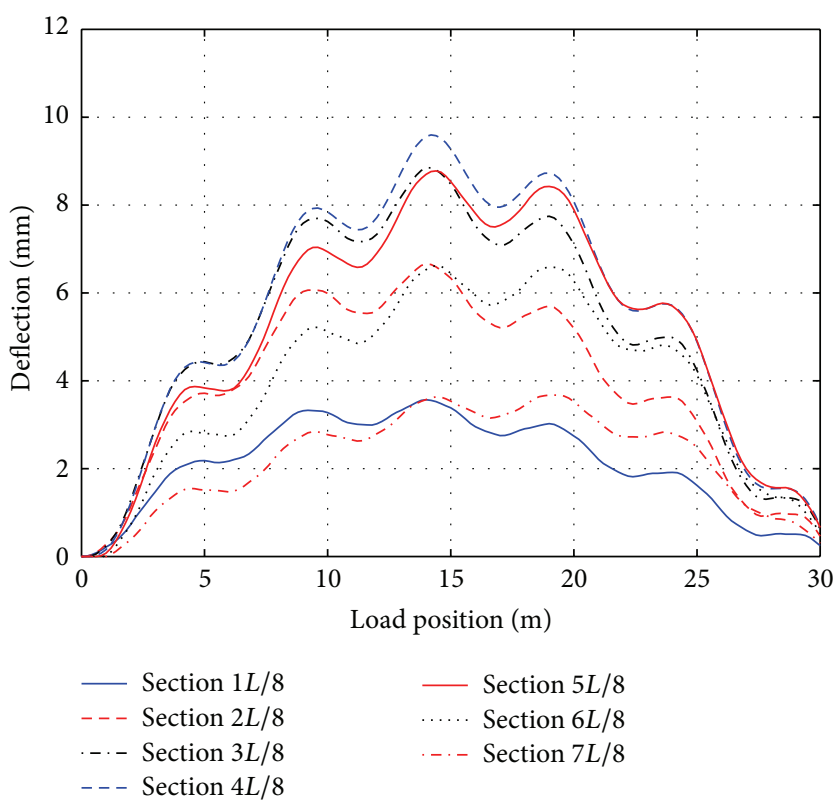

(a) Deflection curve under the load $392 \mathrm{kN}$

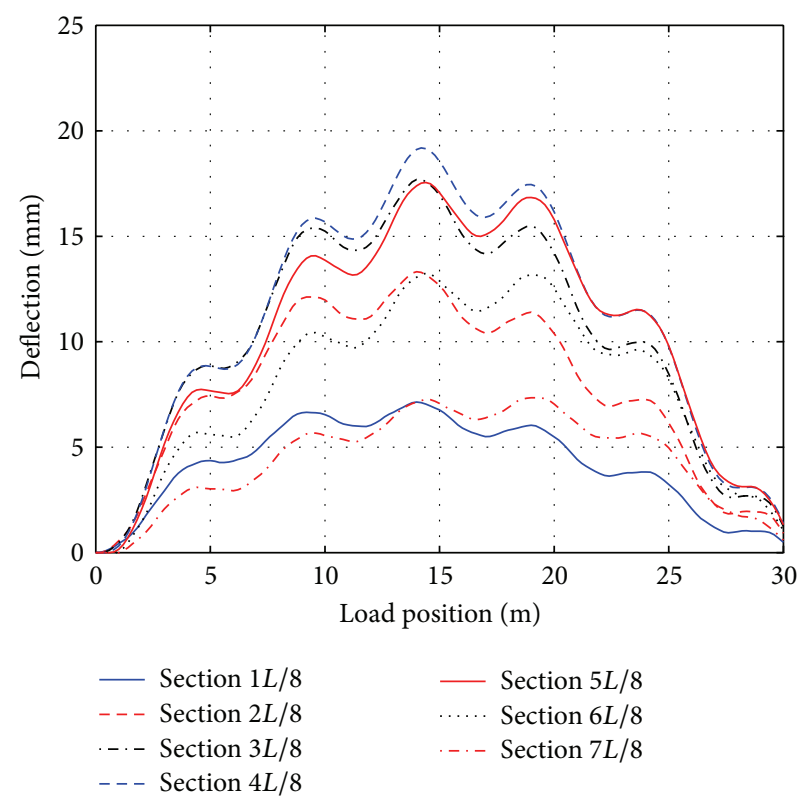

(b) Deflection curve under the load $794 \mathrm{kN}$

Figure 2: The deflection time histories under moving load.

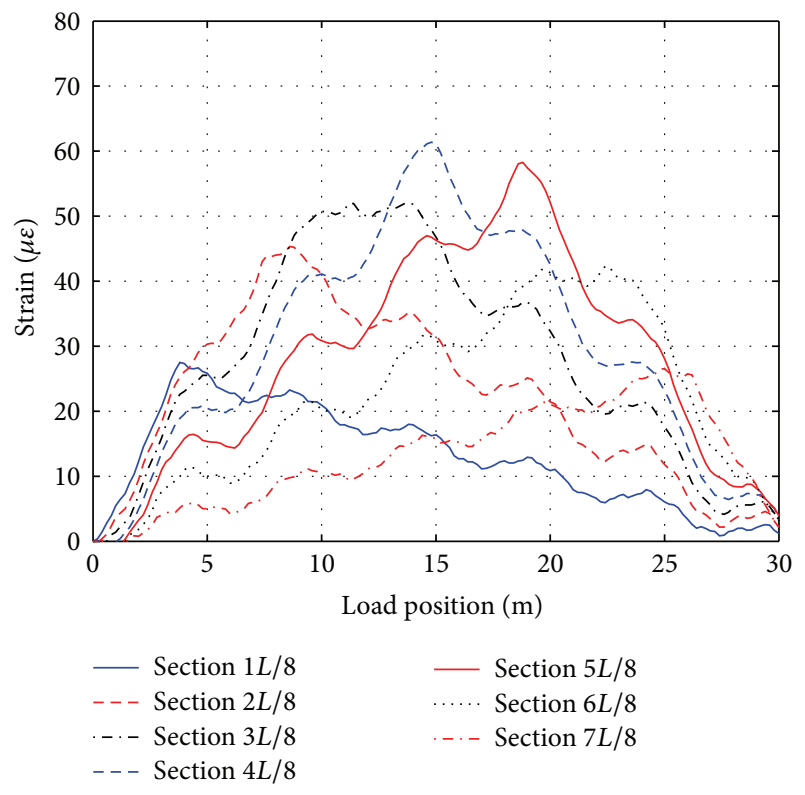

(a) Strain curve under the load $392 \mathrm{kN}$

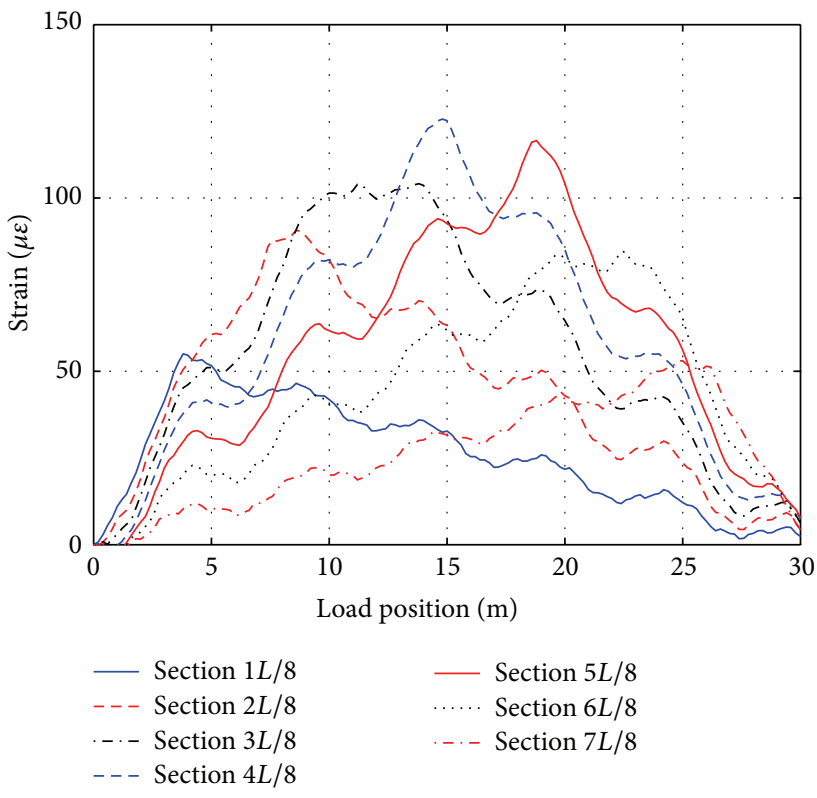

(b) Strain curve under the load $794 \mathrm{kN}$

FIgURE 3: The strain time histories under moving load.

a datum $y_{k}$ (the parameters of the moving loads) from the preceding $n$ data $x_{n}$ (the responses of the bridge). A typical neural network structure is shown in Figure 4.

The network has many nonlinear neurons in every layer to predict the corresponding datum $y_{k}$. The input $\left(x_{n}\right)$ output $\left(y_{k}\right)$ relation of the nonlinear neurons is given by a conventional sigmoid function such as $y=\tanh (x)$ and the input $x$ are expressed by a form $\sum \omega_{i} x_{i}$, where $\omega_{i}$ is a weight for an input component. When the data $x_{n}$ are put into the network, $y_{k}$ is expected to appear at the output after the network being trained; that is, the data $x_{n}$ are given to the input of the network and $y_{k}$ is given to the output as a target. Each weight $\omega_{i}$ in the network is adjusted so as to coincide the output $o_{k}$ with its target $y_{k}$ by a gradient method. That is, for an error function $F$ defined by

$$
F=\sum_{k=S_{t}} \varepsilon_{k}^{2}, \quad \varepsilon_{k}=o_{k}-y_{k},
$$




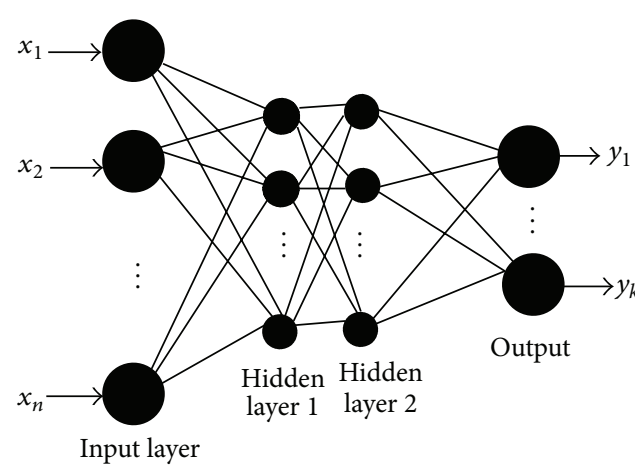

(a) Two hidden layers of BP network topology structure chart

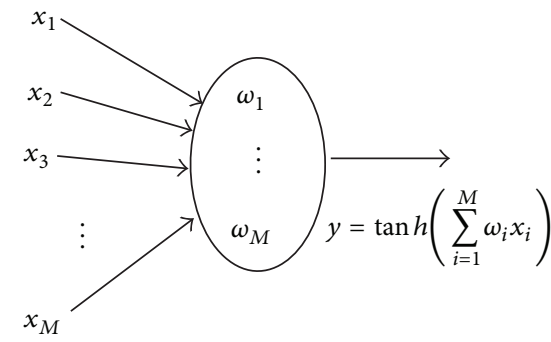

(b) A nonlinear neuron

FIGURE 4: Network structure and nonlinear neuron.

where $S_{t}$ is a set of training patterns, a correction $\delta \omega_{i}$ of $\omega_{i}$ to minimize the error function is given by

$$
\delta \omega_{i}=-\frac{\eta \partial F}{\partial \omega_{i}}
$$

where $\eta$ is a small positive constant. To calculate $\delta \omega_{i}$ for neurons in hidden layers, an error back-propagation (BP) algorithm is used. The training process of BP is divided into two phases. In the first phase (front-propagation), input information is calculated in each hidden layer through the input layer and the output of every neuron is obtained. In the second phase (back-propagation), if the expectant output cannot be obtained, the difference between the actual output and target output can be computed layer by layer in recursion and the weights are adjusted according to this difference until the expectant output is acquired in the out layer.

For loads identification using neural network method, the key means is to design structure of the neural network, which mainly includes the selection and process of network sample; network topology; activation function; and algorithm selection. In this paper, the more commonly used $\mathrm{BP}$ neural network is used to identify the moving loads parameters based on neural network toolbox in numerical analysis software MATLAB. Taking a simply supported beam as an example, the influence of different activation function and algorithm on the network is discussed, and the result is analyzed.

Based on the above discussion, the moving loads identification of the simply supported beam bridge model mentioned above by BPNN is carried out. The vehicle model is simplified into two moving concentrated forces. Dynamic strains under different vehicle loads, wheelbase, and velocity are obtained by numerical calculation. The dynamic strain responses under different combinations of weight, speed, and wheelbase are used as the input of the network, and the loads parameters are used as the output, appropriate network structure and learning algorithm are selected, and the network is established and trained based on partial data. Finally, the capacity of loads identification of the trained network is studied.
3.1. Establishment of Training Sample Database. The strains at the bottom eight points of bridge under moving loads were simulated by finite element software ANSYS. The axle loads of the vehicle are divided into four levels, respectively, including $2940 \mathrm{~kg}, 7840 \mathrm{~kg}, 11760 \mathrm{~kg}$, and $19600 \mathrm{~kg}$. The wheelbases are taken for $3 \mathrm{~m}, 4 \mathrm{~m}, 5 \mathrm{~m}$, and $6 \mathrm{~m}$, and the speeds are set as $5 \mathrm{~m} / \mathrm{s}, 10 \mathrm{~m} / \mathrm{s}, 20 \mathrm{~m} / \mathrm{s}$, and $25 \mathrm{~m} / \mathrm{s}$. The front and rear axle load ratio is $1: 1$. In order to use the least number of samples to get efficient network, $L_{16}\left(4^{3}\right)$ orthogonal table is used to determine the training sample database [29]. The sampling frequency of the strain response is $100 \mathrm{~Hz}$, the total sampling time is 54.14 seconds, and the dynamic responses of the 16 groups of vehicles are obtained. $60 \%$ data are used for training samples, and $20 \%$ data are used for validation, and the other $20 \%$ signals are testing data.

3.2. Analysis and Design of Network Structure. In the BP neural network of load identification, the node number of the input layer is equal to the number of measure points, and the node number of the output layer is equal to the number of parameters to be identified. The sample library is the dynamic strain responses at the bottom of eight equal-part points of the bridge. Therefore, the number of nodes in the input layer is seven. In the identification of the load position, the network output is the vehicle front and rear axle positions, so the output layer node number is 2 . In the identification of the load value, due to the fact that the position of the load has important influence on the result, the identification of load position data is also added to the input data, so the number of nodes in the input layer is nine and the node number of the output layer is still 2 , representing the vehicle's front axle load and rear axle load, respectively.

In determining the network's hidden layer number, due to the complexity and discontinuity of the parameter of loads and the dynamic responses of bridge, the double hidden layer network is used. Hagan et al. pointed that combination of multilayer perceptron and back-propagating learning rules breaks the limitation of linear reparability for single-layer perceptron and can solve any classification problems. In addition, a two-layer neural network is capable of approximating any practical functions as long as the hidden layer 
TABLE 1: Effects of different activation functions on the network.

\begin{tabular}{lccccc}
\hline \multicolumn{2}{c}{ Activation function } & Training time (s) & Iteration number & Mean square error & Correlation coefficient \\
\hline tansig & tansig & 117 & 43 & 3.7265 & 0.9736 \\
logsig & logsig & 118 & 70 & 3.7288 & 0.9948 \\
logsig & tansig & 162 & 59 & 3.6141 & 0.9783 \\
tansig & logsig & 184 & 70 & 2.8518 & 0.9738 \\
\hline
\end{tabular}

TABLE 2: Effects of different training methods on the network.

\begin{tabular}{lccccc}
\hline $\begin{array}{l}\text { Training } \\
\text { algorithm }\end{array}$ & $\begin{array}{c}\text { Training } \\
\text { time (s) }\end{array}$ & $\begin{array}{c}\text { Iteration } \\
\text { number }\end{array}$ & $\begin{array}{c}\text { Mean } \\
\text { square } \\
\text { error }\end{array}$ & Correlation coefficients \\
\hline traingd & 0 & 0 & 1677.6382 & 0.1354 & 0.1348 \\
traingdm & 0 & 0 & 166.6578 & 0.6972 & 0.4948 \\
traingdx & 12 & 90 & 12.6659 & 0.9311 & 0.9373 \\
trainbfg & 51 & 48 & 5.0487 & 0.9601 & 0.9880 \\
trainrp & 198 & 299 & 3.9941 & 0.9623 & 0.9871 \\
trainlm & 145 & 50 & 2.4951 & 0.9772 & 0.9961 \\
\hline
\end{tabular}

has enough neurons and the transfer function is sigmoid function [30]. In the selection of the hidden layer nodes, the combinations of different nodes numbers are compared. Finally, the combination of minimum errors is selected, the nodes composition of the loads position identification network is 7-21-10-2, and the nodes composition of the loads value identification network is 9-21-10-2.

3.3. Determination of Activation Function and Algorithm. The conventional activation functions in BP neural network are logsig and tansig. The training algorithms are mainly traingd (traditional gradient descent method), traingdm (gradient descent method with momentum), traingdx (learning rate adaptive adjustment algorithm), trainbfg (quasiNewton method), trainrp (elastic gradient descent algorithm), and trainlm (Levenberg-Marquardt algorithm). In order to compare the effects of different activation functions and algorithms on network performance and select the best activation function and training algorithm, the influence of different activation function and algorithm on the network is calculated. The output results of the network simulation and the output of the target are analyzed by linear regression analysis, and the correlation coefficients are obtained. And the results of the training time and the value of error function of the training are added to consider as the basis for evaluating the results of the network training. The comparison results are shown in Tables 1 and 2.

According to Table 1, it can be seen that the convergence time of different transfer functions is different, and the earlier the convergence the higher the mean square error value. The different combinations of activation functions have very small influence on correlation coefficients. The number of iterations is not proportional to the training time. This shows that the initial weights and thresholds of each training network are random, and the gradient direction of error decreases is different. In order to obtain the high accuracy of the network model, tansig is used as the activation function of the first hidden layer, and logsig is used as the activation function of the second hidden layer.

It can be seen from Table 2 that different training algorithms have a great impact on the accuracy of the network. The network will fall directly into the local minimum with the traditional gradient descent method and the gradient descent method with momentum, and the available network model cannot be established. Several other improved gradient descent algorithms can construct available network, and the correlation coefficient, the training time, and the mean square error values are slightly different. Upon comprehensive consideration, trainlm is used as the training function of the network.

3.4. Accuracy Evaluation of the Network. To evaluate the accuracy of the identified results, the relative output error and the correct recognition rate are used as the evaluation index of the network. The relative output error of the network is the ratio of the distance between the actual output and the ideal output vector of the network to the norm of the ideal output vector [31], giving

$$
\operatorname{Re}=\frac{\sum_{i=1}^{m}\left\|y_{i}-t_{i}\right\|}{(1 / m) \sum_{i=1}^{m}\left\|t_{i}\right\|}
$$

where $\|\cdot\|$ is the norm of a vector, $y_{i}$ is the actual output of the network, $t_{i}$ is the ideal output of the network, and $m$ is the number of test samples.

The correct recognition rate of the network is the ratio of the sample number, in which the relative error is less than $10 \%$, to the total sample number. In general, it is believed that the network has practical value if the correct recognition rate is more than $60 \%$ [32].

\section{Identification Result Analysis}

4.1. Identification Results of the Constant Loads. The identification results of the vehicle's front and rear axle position are shown in Figures 5 and 6 . If the vehicle's axle is not on the bridge, the output will be zero, and when it is on the bridge, the output is the distance from the load to the entrance of the bridge. It can be seen that the identified position curve is close to the true position curve. There is only a very small deviation near the bridge support. Hence, the identification accuracy will be improved by only selecting the data that the vehicle is completely on the bridge, when the vehicle speed is identified. Furthermore, the entrance time and leave time of the front and rear axle on the bridge can be determined distinctly, so whether the axle is on the bridge can be well identified. 


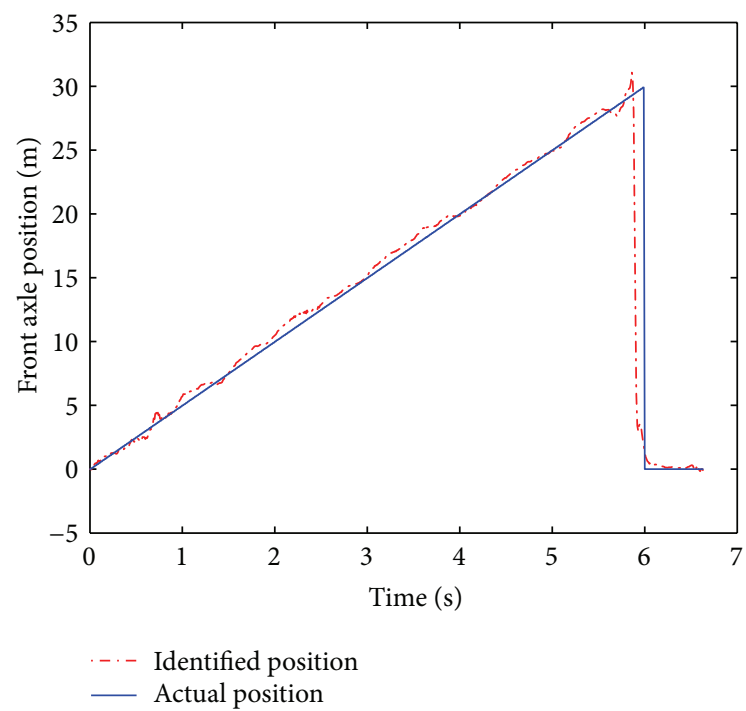

FIGURE 5: Identified position of the front axle.

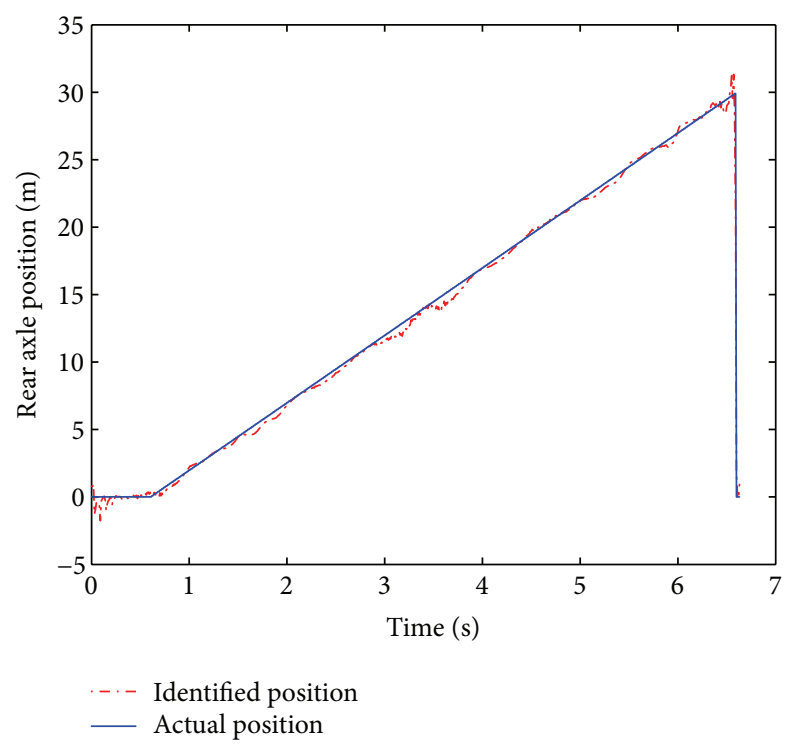

Figure 6: Identified position of the rear axle.

Because the front axle location minus rear axle position of the vehicle is the wheelbase, the wheelbase identification is realized by the location identification. For the identification of the vehicle wheelbase, the data that two axles are both on the bridge are selected and the identification results are shown in Table 3. It can be seen that the accuracy of the network has a great change when the wheelbase is identified. The identification results are usually better if the wheelbase is larger and the speed is lower, and vice versa.

Once the loads positions are identified, the amplitude of the response is regarded only related to the magnitude value of loads. Therefore, when the network is trained to identify the load value of the axle, the identified location information and the strain response information are used as the input of the network, and the front and rear axles load values are set

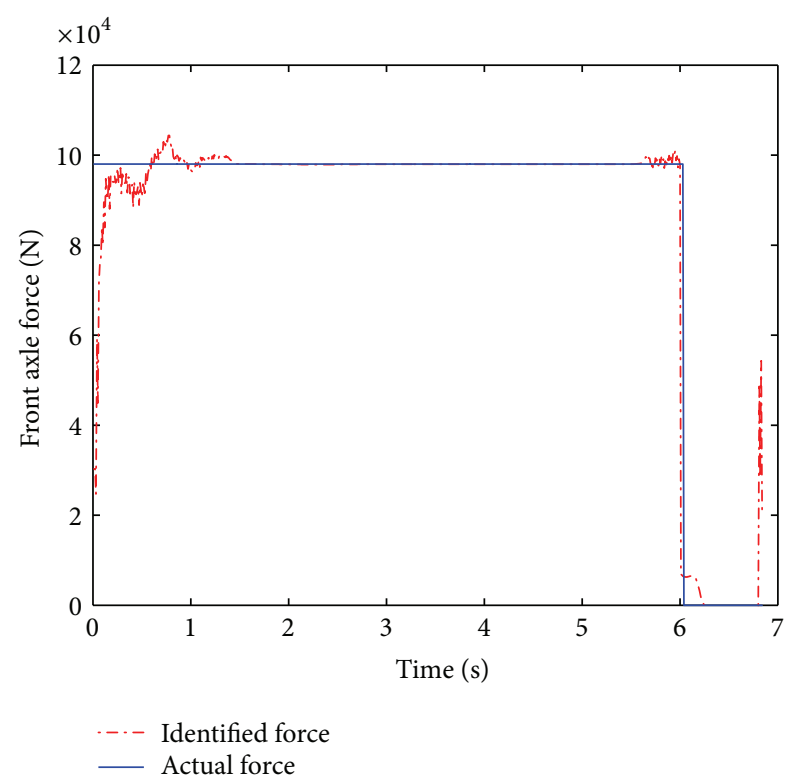

FIgURE 7: Identified value of the front axle load.

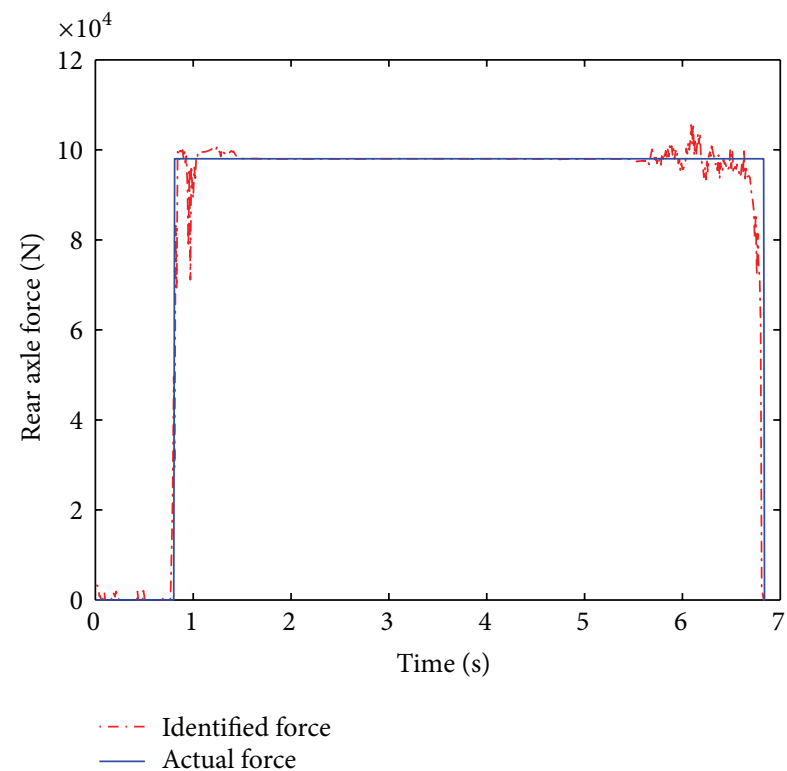

FIGURE 8: Identified value of the rear axle load.

as the output of the network. The vehicle's front and rear axles identification results are, respectively, shown in Figures 7 and 8. The identification accuracy is adequate when the vehicle is completely on the bridge; the larger error still occurs when the vehicle moves into and leaves the bridge. Likewise, whether the load is on the bridge can be clearly distinguished.

The correct recognition rates of the load identification network under different axle loads and speeds are shown in Table 4. It can be seen that almost all of the network correct recognition rates are more than $60 \%$ in all cases, and higher correct recognition rate will be achieved if the vehicle speed is low and the wheelbase is small. 
TABLE 3: Correct recognition rate of wheelbase in different speeds.

\begin{tabular}{lcccc}
\hline \multirow{2}{*}{ Wheelbase $(\mathrm{m})$} & \multicolumn{4}{c}{ Speed $(\mathrm{m} / \mathrm{s})$} \\
& 5 & 10 & 20 & 25 \\
\hline 3 & 73.93 & 66.67 & 46.53 & 47.50 \\
4 & 88.32 & 85.99 & 34.62 & 34.52 \\
5 & 87.94 & 82.16 & 58.88 & 61.63 \\
6 & 88.28 & 90.87 & 64.55 & 70.45 \\
\hline
\end{tabular}

TABLE 4: Correct recognition rate of load value in different wheelbases and speeds.

\begin{tabular}{|c|c|c|c|c|}
\hline \multirow{2}{*}{ Wheelbase (m) } & \multicolumn{4}{|c|}{ Speed $(\mathrm{m} / \mathrm{s})$} \\
\hline & 5 & 10 & 20 & 25 \\
\hline \multicolumn{5}{|l|}{3} \\
\hline Front axle & 76.20 & 83.13 & 85.54 & 87.97 \\
\hline Rear axle & 68.67 & 81.02 & 79.52 & 86.47 \\
\hline \multicolumn{5}{|l|}{4} \\
\hline Front axle & 85.96 & 74.27 & 76.61 & 81.75 \\
\hline Rear axle & 85.82 & 66.67 & 75.44 & 75.18 \\
\hline \multicolumn{5}{|l|}{5} \\
\hline Front axle & 81.82 & 83.24 & 60.23 & 72,34 \\
\hline Rear axle & 81.11 & 83.81 & 66.48 & 68.79 \\
\hline \multicolumn{5}{|l|}{6} \\
\hline Front axle & 79.28 & 78.45 & 81.22 & 53.79 \\
\hline Rear axle & 71.69 & 79.28 & 79.56 & 60.69 \\
\hline
\end{tabular}

TABLE 5: Vehicle speed identification results with different wheelbases.

\begin{tabular}{|c|c|c|c|c|}
\hline \multirow{2}{*}{ Wheelbase (m) } & \multicolumn{4}{|c|}{ Actual speed $(\mathrm{m} / \mathrm{s})$} \\
\hline & 5 & 10 & 20 & 25 \\
\hline \multicolumn{5}{|l|}{3} \\
\hline Identified speed (m/s) & 4.9742 & 9.9619 & 20.0291 & 24.6465 \\
\hline Relative error (\%) & 0.52 & 0.38 & 0.15 & 1.41 \\
\hline \multicolumn{5}{|l|}{4} \\
\hline Identified speed (m/s) & 5.0206 & 9.8656 & 20.5416 & 25.5117 \\
\hline Relative error (\%) & 0.41 & 1.34 & 2.71 & 2.05 \\
\hline \multicolumn{5}{|l|}{5} \\
\hline Identified speed (m/s) & 4.9981 & 10.0727 & 20.3806 & 25.6549 \\
\hline Relative error (\%) & 0.04 & 0.73 & 1.9 & 2.62 \\
\hline \multicolumn{5}{|l|}{ 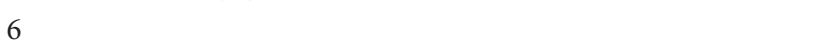 } \\
\hline Identified speed (m/s) & 4.9666 & 9.8695 & 20.2944 & 25.6746 \\
\hline Relative error (\%) & 0.67 & 1.3 & 1.47 & 2.7 \\
\hline
\end{tabular}

The slope of the vehicle position curve is the speed of the vehicle. Therefore, when the vehicle is completely on the bridge, the position curve is fitted and the slope of the fitted curve is calculated; thus, the average speed of the vehicle is obtained. The speed identification results with different speeds and wheelbases of the vehicle are listed in Table 5. The maximum relative error of the identified results is $2.7 \%$, when the wheelbase is $6 \mathrm{~m}$ and the speed is $25 \mathrm{~m} / \mathrm{s}$. The general trend is that the recognition accuracy is higher when the speed and wheelbase of the vehicle are small, and for the same
TABLE 6: Effect of different noise levels on recognition effect.

\begin{tabular}{lcccc}
\hline \multirow{2}{*}{ Correct recognition rate } & \multicolumn{4}{c}{ Noise level } \\
& $5 \%$ & $10 \%$ & $15 \%$ & $20 \%$ \\
\hline Before filtering & $79.60 \%$ & $63.21 \%$ & $51.51 \%$ & $41.47 \%$ \\
After filtering & $83.61 \%$ & $83.61 \%$ & $77.59 \%$ & $63.55 \%$ \\
\hline
\end{tabular}

wheelbase the recognition accuracy of speed decreases with the increased speed.

4.2. Identification Results of the Dynamic Axle Loads. In order to verify the identification effect of the loads varying with time by network, the vehicle's axle loads on the bridge assume the trigonometric function as $P=39.2 \times(1+0.15 \times$ $\cos (13.35)) \mathrm{kN}$, the speed $v$ is $10 \mathrm{~m} / \mathrm{s}$, and the wheelbase is $6 \mathrm{~m}$. The identification results are shown in Figures 9 and 10, and the recognition result of the front axle is better than the rear axle, and the loads frequency can be identified. By adding different levels of noise in the sample, the effect of noise on the recognition results is shown in Table 6. The noise has great impact on the identification accuracy, but when adding $10 \%$ of the noise, the network correct recognition rate is still greater than $60 \%$, which shows that the network has a good fault tolerance. After signal filtering technique is used, even the noise level reaches $20 \%$, the correct rate of the network is still higher than $60 \%$, indicating that the network is still valid in this case.

\section{Model Experiment and Identification Using ANN}

The experimental simulation of a vehicle moving on a bridge is carried out to investigate the effect of the previously presented identification methods for dynamic axle loads by the bottom strains of the bridge. When the BP neural network is used to identify the moving loads of the actual structure, the finite element model of the actual structure is firstly established, the responses of the bridge are simulated, and the simulated responses of the bridge are compared with the measured responses to ensure that the finite element model is accurate. Then the effective finite element model is used to simulate the responses of the bridge under different conditions, and the network is trained by the vehicle loads information and the bridge response information. The trained neural network will have the capability of identifying the moving loads from the bridge responses. Then the measured response information of the bridge is used as input of the network, and the loads information can be obtained. The corresponding load identification by BP neural network strategy flowchart is shown in Figure 11.

The composition and the cross section mechanism of the experimental model are shown in Figures 12 and 13, respectively. The deck of the bridge model is made of a uniform thickness steel plate and is divided into three spans consisting of a leading span, a main span, and a trailing span. Leading span and trailing span are used for acceleration and deceleration of the vehicle model, respectively. The auxiliary 


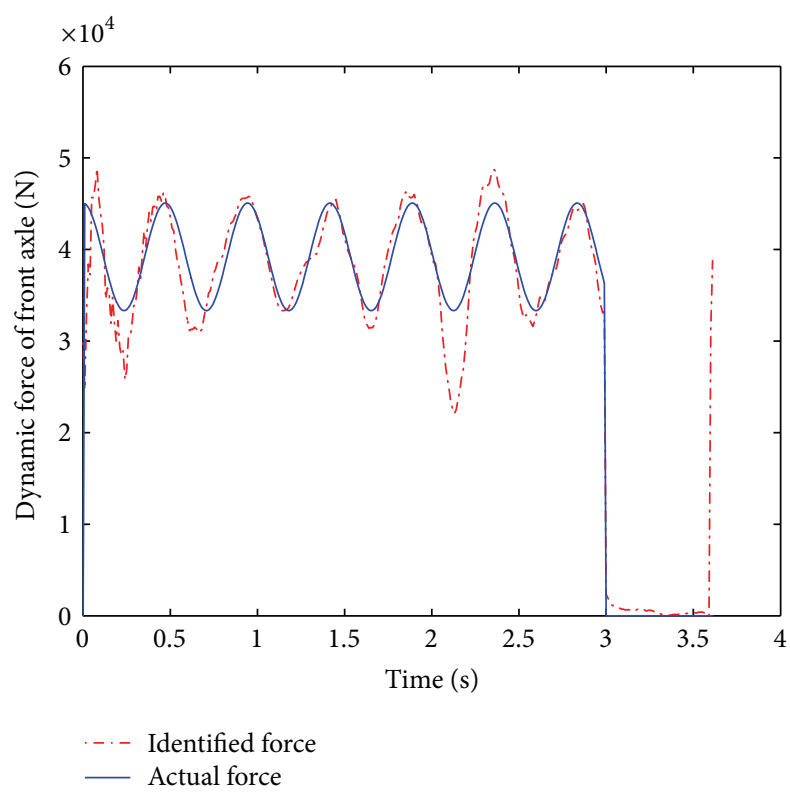

FIGURE 9: Identified value of the front dynamic axle load.

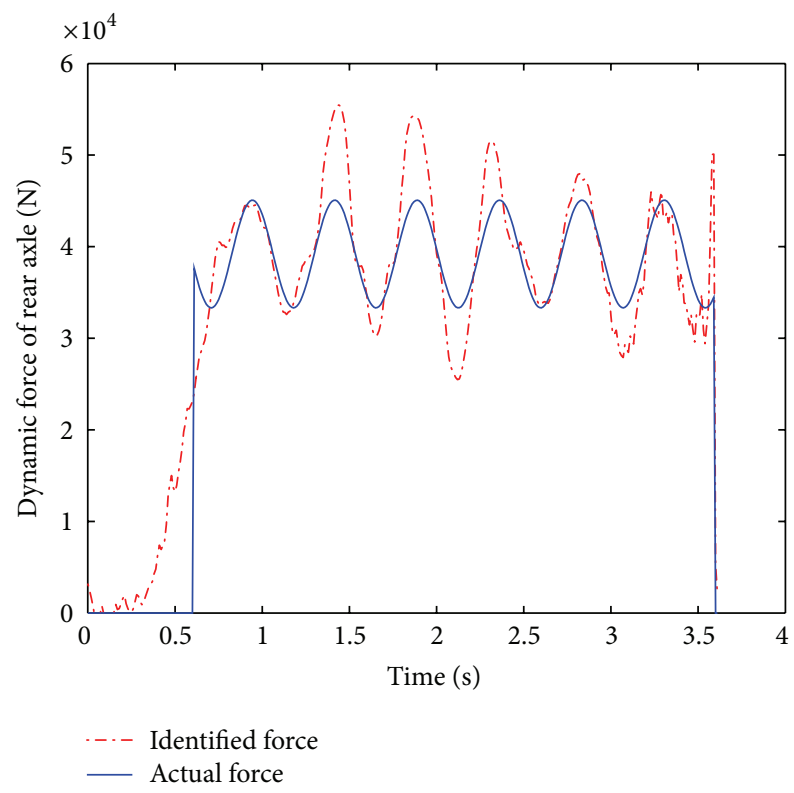

FIGURE 10: Identified value of the rear dynamic axle load.

beam and the main girder share a bearing, and there is a small gap between them, and foam filled in the gap to reduce the impact loads caused by the vehicle when it steps on and leaves the bridge. Since the deck of the main span is well separated from the two side spans, it is free from the structural continuity of the side spans. Consequently, the main span can be treated as a simply supported bridge. The bridge model parameters are as follows: the length of the beam $L$ is $2 \mathrm{~m}$ with a $10 \mathrm{~mm} \times 150 \mathrm{~mm}$ uniform cross section, the elastic modulus $E$ is $2.07 \times 10^{11} \mathrm{~N} / \mathrm{m}^{2}$, the moment of inertia $I=1.295 \times 10^{-8} \mathrm{~m}^{4}$, and the density $\rho=7850 \mathrm{~kg} / \mathrm{m}^{2}$. A U-shaped aluminum section is glued to the upper surface of the beams as a direction guider for the vehicle model. A vehicle model having two axles and two rubber wheels for each axle is employed.

In order to measure the dynamic strain responses of the bridge under moving vehicles, seven strain gauges are installed at each cross section at the $1 / 8$ to $7 / 8$ span. Nine steel bars are arranged at equal space on one side of the main girder, and a sheet steel with a strain gauge is fixed on the vehicle model; when the model vehicle passes through the model beam, the sheet steel on the model vehicle will hit the steel bar, the vibration signal will be recorded by the strain gauge on the sheet steel, and the speed of the model vehicle can be obtained by analyzing the signal of the voltage.

The completed model beam and model car are shown in Figures 14 and 15. The weight of the model car varied as $9.38 \mathrm{Kg}, 16.26 \mathrm{Kg}$, and $20.42 \mathrm{Kg}$ by adjusting the weight on the car, and the speed varied as $0.33 \mathrm{~m} / \mathrm{s}, 0.66 \mathrm{~m} / \mathrm{s}$, or $1.00 \mathrm{~m} / \mathrm{s}$, and the wheelbase is $20 \mathrm{~cm}$ and $25 \mathrm{~cm}$, respectively, and 18 groups of signals for different cases are collected.

The strain responses at the bottom of the model beam under the model vehicle moving are shown in Figure 16; in this case, the model vehicle's weight is $9.38 \mathrm{Kg}$, front and rear axles load ratio is $1: 1$, wheelbase is $25 \mathrm{~cm}$, speed is $0.25 \mathrm{~m} / \mathrm{s}$, and sampling frequency is $1000 \mathrm{~Hz}$. It can be seen from Figure 16 that the strain curves of the measuring points are symmetrical, and the peak point varies with the relative position between the vehicle and the measuring point; the linear degree of strain curves at 1/8 and 7/8 span is slightly poor, but strain curves at other points of measurement are superior.

Because the time-varying loads of the vehicle are unknown in the test, the accurate and reasonable target results for network learning are indefinite; therefore, the software ANSYS is used to establish the finite element model, as shown in Figure 17, and the test process under different experimental conditions is simulated; the simulation samples are obtained. In order to verify the rationality of the finite element model, the comparison between the test and the simulation strain curve at midspan of the main beam is shown in Figure 18. It is obvious that the simulation results are reasonable.

After the simulation data is obtained, the network is trained with the method mentioned above, and then the trained network is used to identify the parameters of loads; in this case, the vehicle's weight is $9.2 \mathrm{~kg}$, the speed is $0.35 \mathrm{~m} / \mathrm{s}$, and the axle load ratio is $1: 1$.

The position identification results of the model vehicle are shown in Figures 19 and 20, and the front axle identification result is better than the result of the rear axle. Overall, the identification of the position curve and the ideal curve is in good agreement. The main identification error occurs when the model vehicle moves into and leaves the bridge. This identification error is mainly caused by the relatively small signal-to-noise ratio of the strain response when the vehicle's position is close to the supports.

The position curve is fitted and the slope of the obtained line is the speed of the vehicle model. The average speed identification results of the model vehicle with different speeds are listed in Table 7. As can be seen from the table, 


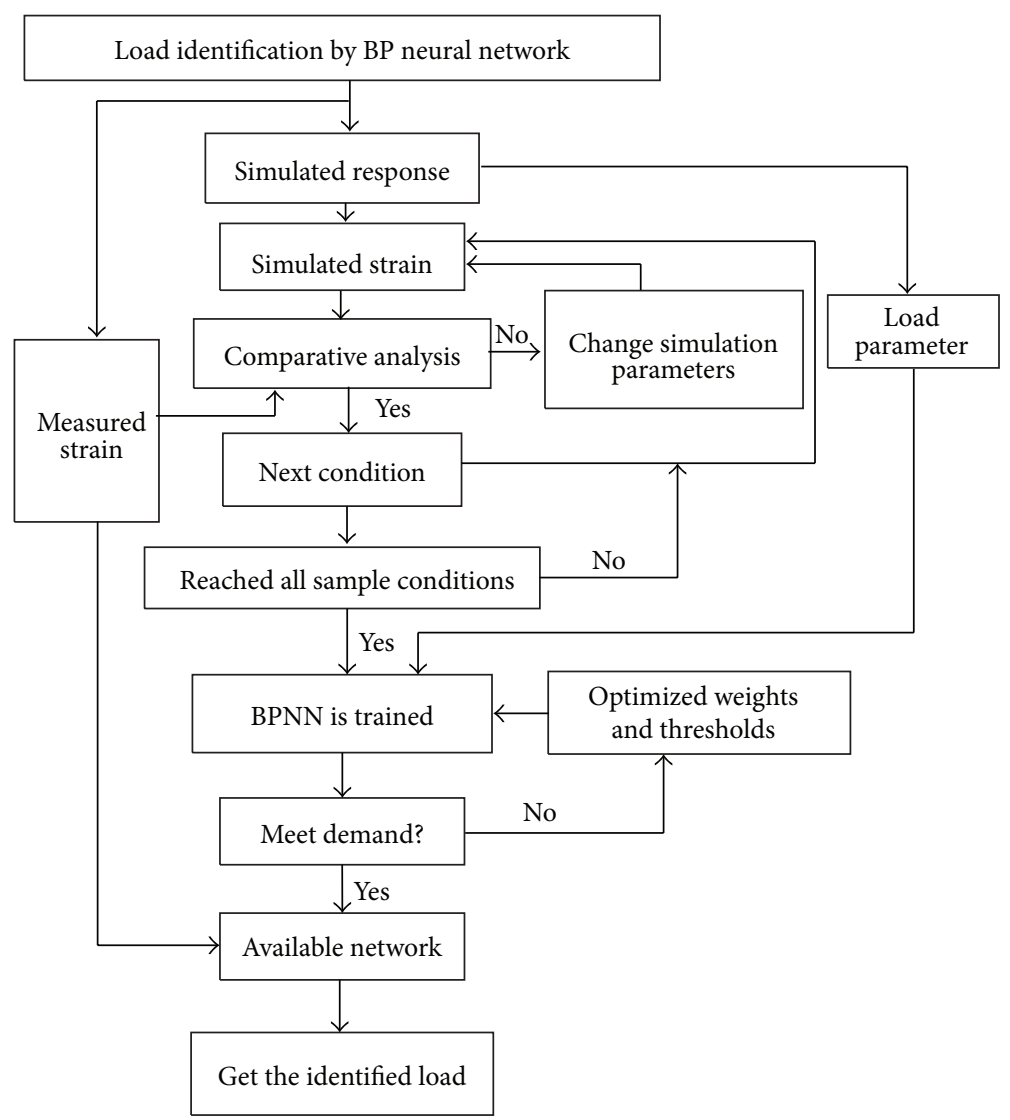

FIGURE 11: Flowchart for load identification by BP neural network.

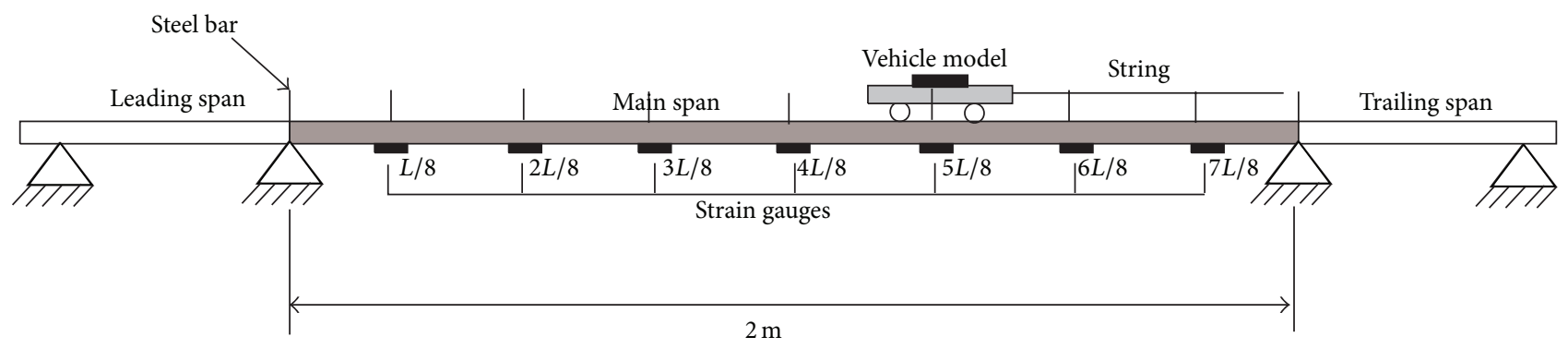

FIGURE 12: Experiment setup.

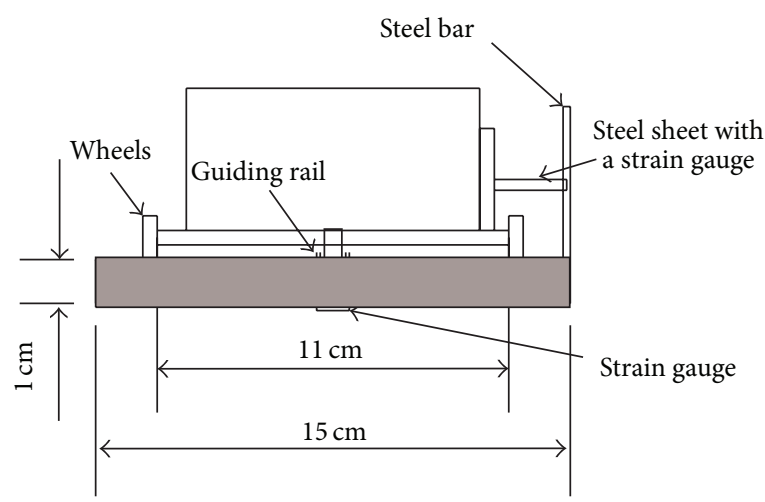

FIGURE 13: Cross-sectional of vehicle-bridge model. 


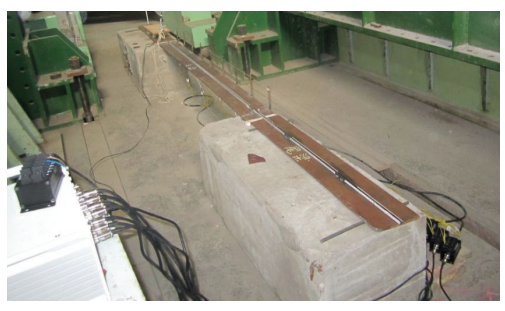

FIGURE 14: Model beam.

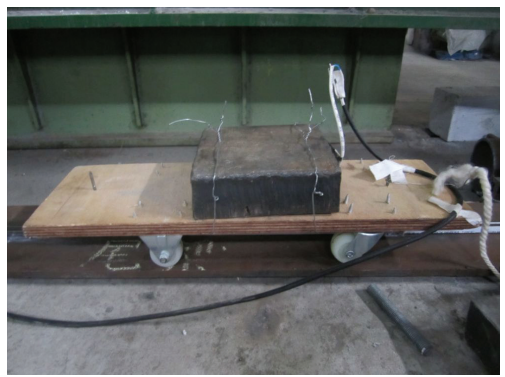

Figure 15: Model vehicle.

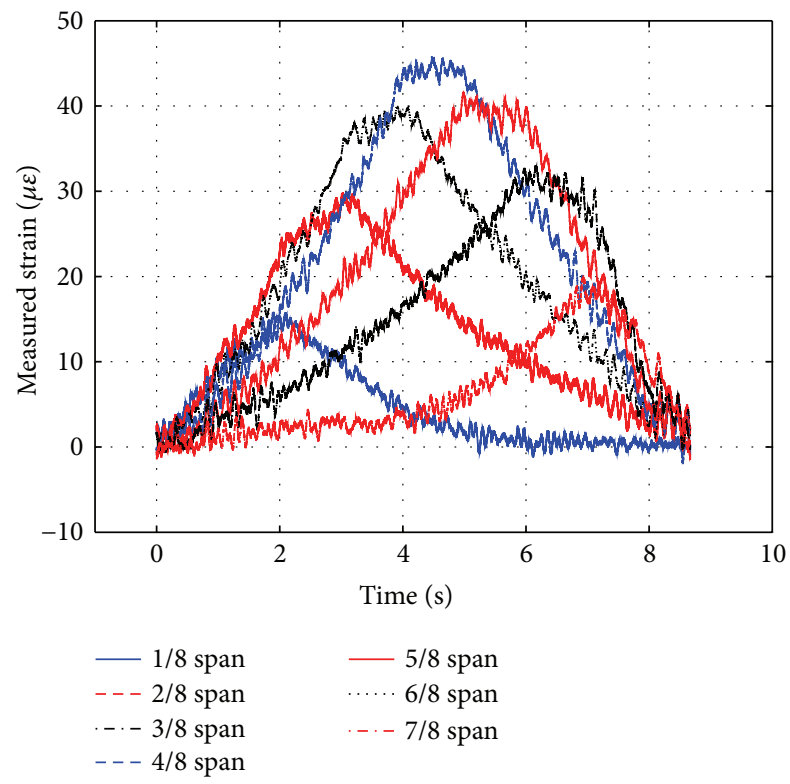

FIgURE 16: A sample of dynamic strain response.

TABLE 7: Average speed identification results of model vehicle.

\begin{tabular}{lccccc}
\hline Measured speed $(\mathrm{m} / \mathrm{s})$ & 0.3337 & 0.5213 & 0.7069 & 1.0847 & 1.2681 \\
\hline Identified speed (m/s) & 0.3479 & 0.5413 & 0.7308 & 1.1108 & 1.2975 \\
Absolute error $(\mathrm{m} / \mathrm{s})$ & 0.0142 & 0.0210 & 0.0239 & 0.0261 & 0.0294 \\
Relative error $(\%)$ & 4.26 & 4.02 & 3.38 & 2.41 & 2.32 \\
\hline
\end{tabular}

the identification results of the vehicle's speed are accurate, and the absolute error of identification becomes larger with the increase of the speed. The relative error decreases with the increase of the speed.

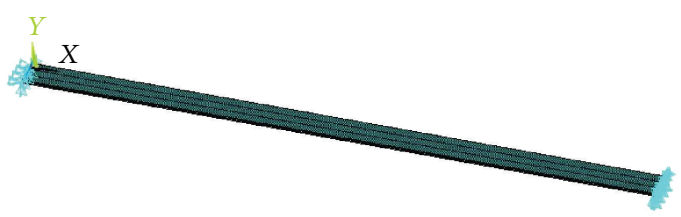

FIGURE 17: Finite element model of model beam.

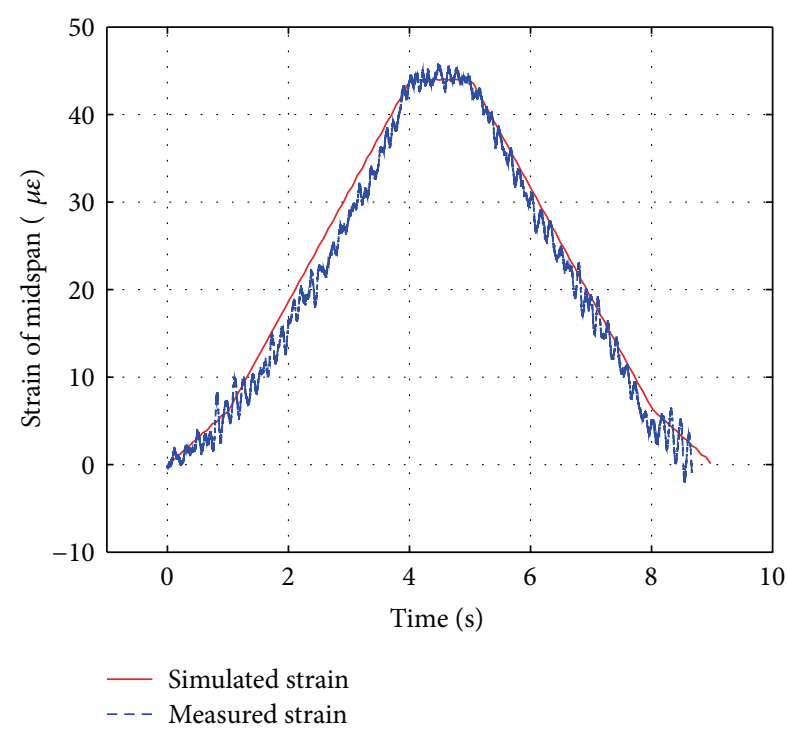

FIGURE 18: Comparison of measured and simulated strain of midspan.

TABLE 8: Position identification error results of model vehicle.

\begin{tabular}{lccccc}
\hline Speed $(\mathrm{m} / \mathrm{s})$ & 0.3337 & 0.5213 & 0.7069 & 1.0847 & 1.2681 \\
\hline $\begin{array}{l}\text { Maximum } \\
\text { position }\end{array}$ & 0.085 & 0.001 & 0.088 & 0.481 & 0.464 \\
$\begin{array}{l}\text { identification } \\
\text { error }(\mathrm{m})\end{array}$ & & & & & \\
\hline
\end{tabular}

The identification error of vehicle's position can be obtained by multiplying the vehicle's speed by the total time of the vehicle passing through the bridge; the result is shown in Table 8. It can be seen that, with the increase of the speed, the position error is gradually increasing, especially when the vehicle's speed is higher; that is, the speed error can lead to large position errors, so it is important to identify the speed correctly.

The dynamic identification results of the vehicle's front and rear axle loads are shown in Figures 21 and 22, respectively, compared with the axial static load. It can be seen that the identified force varies around the static axial load of the vehicle, and a clear pitching motion of the vehicle can be observed from the time histories. It is worth noting that the maximum value of the loads identified is much greater than the static load value when the vehicle enters and leaves the bridge, and this is mainly caused by the impact load of the vehicle when moving through the gap at the link between model beams. 


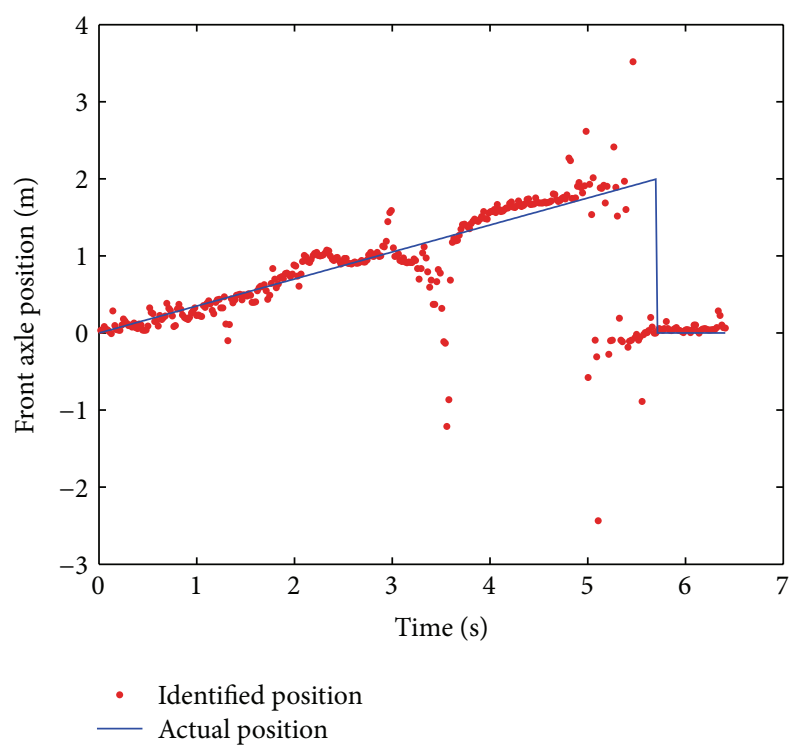

FIGURE 19: The position identification results of the model vehicle (front axle).

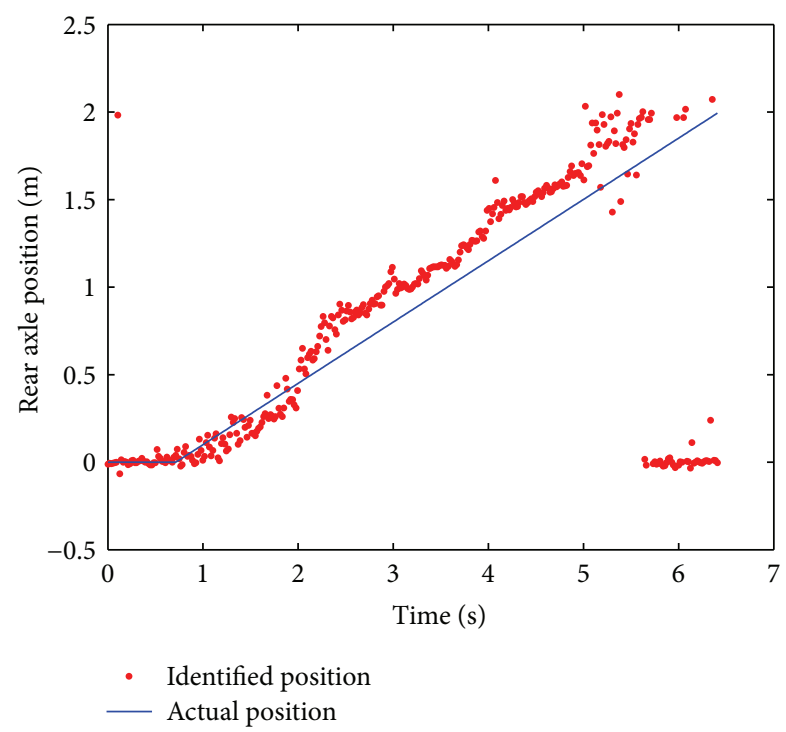

FIGURE 20: The position identification results of the model vehicle (rear axle).

\section{Conclusion}

For vehicle-bridge dynamic system, axle load identification is a classic inverse problem. The dynamic strain is selected to identify the loads parameter because it is sensitive to both load location and load value. In order to overcome the computing deficiency of the traditional identification method, BP neural network is applied to identify the moving loads, and the accuracy is verified by experiments. The results show that the BP neural network method is feasible for moving load identification, which can be used to identify the position, the wheelbase, and the dynamic loads of the vehicle based on dynamic strain responses of the bridge

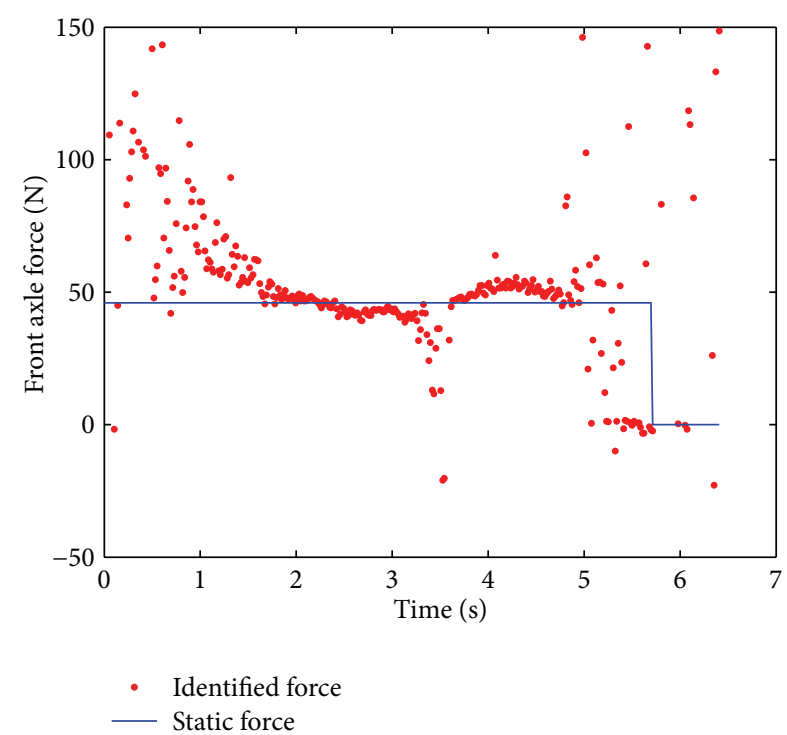

FIgure 21: The front axle force identification results of the model vehicle.

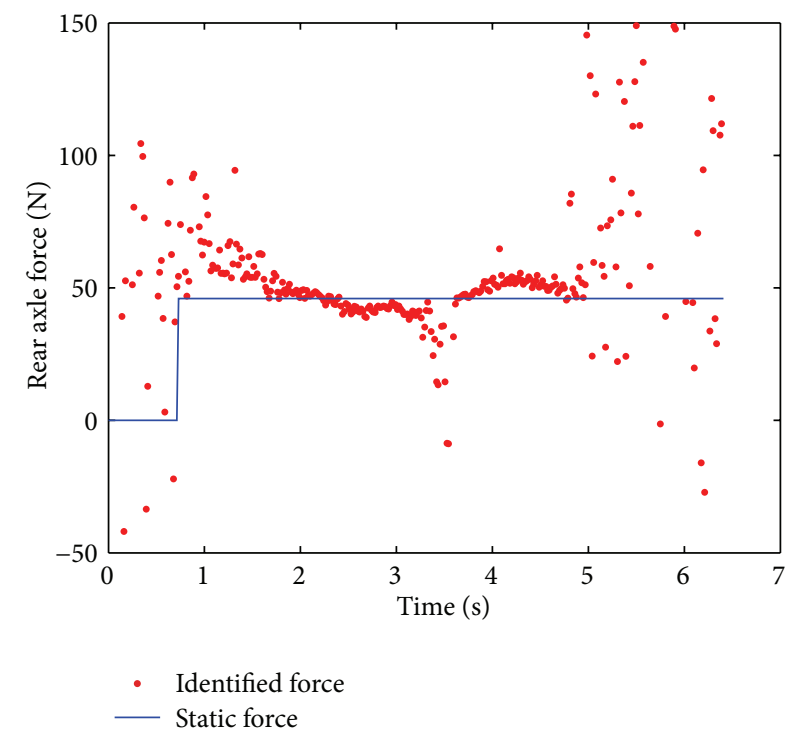

FIGURE 22: The rear axle force identification results of the model vehicle.

subjected to moving loads. In the application of neural network for moving load identification, the transfer function in different combinations has little effect on the results, but the different training methods have a great influence on the results. The identification for the constant moving load has a higher recognition accuracy; the identification results of the time-varying force are not so better, but it is still able to recognize the load value. The values of the identified force are consistent with the actual regularity and have good antinoise performance. The identification method of moving load using ANN and dynamic strain can be used as a simple, low-cost, and convenient means for short-term monitoring or condition assessment for bridge inspection. 


\section{Competing Interests}

The authors declare that they have no competing interests.

\section{Acknowledgments}

This work is partially supported by the Natural Science Foundation of China under Grants nos. 51478024 and 51108009 and the Foundation of Beijing Key Lab of Earthquake Engineering and Structural Retrofit under Grant no. USDE201403.

\section{References}

[1] H. Nishida, H. Sato, H. Kawai, and S. Nakao, "Special vehicle automatic measurement system and its application," in Proceedings of the 5th International Conference on Weigh-in-Motion of Heavy Vehicles (ICWIM '08), 2008.

[2] L. Deng and C. S. Cai, "Identification of dynamic vehicular axle loads: theory and simulations," Journal of Vibration and Control, vol. 16, no. 14, pp. 2167-2194, 2010.

[3] S. S. Law, T. H. T. Chan, and Q. H. Zeng, "Moving force identification: a time domain method," Journal of Sound and Vibration, vol. 201, no. 1, pp. 1-22, 1997.

[4] S. S. Law, T. H. T. Chan, and Q. H. Zeng, "Moving force identification-a frequency and time domains analysis," Journal of Dynamic Systems, Measurement and Control, vol. 121, no. 3, pp. 394-401, 1999.

[5] S. S. Law, J. Q. Bu, X. Q. Zhu, and S. L. Chan, "Vehicle axle loads identification using finite element method," Engineering Structures, vol. 26, no. 8, pp. 1143-1153, 2004.

[6] Y. X. Rong, "Vibration response curve moving fitting method and moving forces identification," Noise and Vibration Control, vol. 26, no. 3, pp. 42-43, 2006.

[7] L. Zhong Xian and C. Feng, "Identification and parametric analysis of moving loads on simply supported and multi-span continuous bridges," Engineering Mechanics, vol. 23, no. 12, pp. 91-99, 2006.

[8] H. Adeli and S. L. Hung, Machine Learning: Neural Networks, Genetic Algorithms, and Fuzzy Systems, John Wiley \& Sons, New York, NY, USA, 1995.

[9] S. Gholizadeh, E. Salajegheh, and P. Torkzadeh, "Structural optimization with frequency constraints by genetic algorithm using wavelet radial basis function neural network," Journal of Sound and Vibration, vol. 312, no. 1-2, pp. 316-331, 2008.

[10] S. Gholizadeh and E. Salajegheh, "Optimal design of structures subjected to time history loading by swarm intelligence and an advanced metamodel," Computer Methods in Applied Mechanics and Engineering, vol. 198, no. 37-40, pp. 2936-2949, 2009.

[11] S. Gholizadeh, J. Salajegheh, and E. Salajegheh, "An intelligent neural system for predicting structural response subject to earthquakes," Advances in Engineering Software, vol. 40, no. 8, pp. 630-639, 2009.

[12] S. Gholizadeh and E. Salajegheh, "Optimal seismic design of steel structures by an efficient soft computing based algorithm," Journal of Constructional Steel Research, vol. 66, no. 1, pp. 85-95, 2010.

[13] K. Kawamura, A. Miyamoto, D. M. Frangopol, and R. Kimura, "Performance evaluation of concrete slabs of existing bridges using neural networks," Engineering Structures, vol. 25, no. 12, pp. 1455-1477, 2003.
[14] W. T. Yeung and J. W. Smith, "Damage detection in bridges using neural networks for pattern recognition of vibration signatures," Engineering Structures, vol. 27, no. 5, pp. 685-698, 2005.

[15] J. J. Lee and C. B. Yun, "Damage diagnosis of steel girder bridges using ambient vibration data," Engineering Structures, vol. 28, no. 6, pp. 912-925, 2006.

[16] M. Mehrjoo, N. Khaji, H. Moharrami, and A. Bahreininejad, "Damage detection of truss bridge joints using artificial neural networks," Expert Systems with Applications, vol. 36, no. 3, pp. 1122-1131, 2008.

[17] C.-B. Yun, J.-H. Yi, and E. Y. Bahng, "Joint damage assessment of framed structures using a neural networks technique," Engineering Structures, vol. 23, no. 5, pp. 425-435, 2001.

[18] C. S. Huang, S. L. Hung, C. M. Wen, and T. T. Tu, "A neural network approach for structural identification and diagnosis of a building from seismic response data," Earthquake Engineering \& Structural Dynamics, vol. 32, no. 2, pp. 187-206, 2003.

[19] J. L. Zapico and M. P. González, "Numerical simulation of a method for seismic damage identification in buildings," Engineering Structures, vol. 28, no. 2, pp. 255-263, 2006.

[20] H. F. Lam and C. T. Ng, "The selection of pattern features for structural damage detection using an extended Bayesian ANN algorithm," Engineering Structures, vol. 30, no. 10, pp. 27622770, 2008.

[21] O. R. de Lautour and P. Omenzetter, "Prediction of seismicinduced structural damage using artificial neural networks," Engineering Structures, vol. 31, no. 2, pp. 600-606, 2009.

[22] K.-V. Yuen and H.-F. Lam, "On the complexity of artificial neural networks for smart structures monitoring," Engineering Structures, vol. 28, no. 7, pp. 977-984, 2006.

[23] B. Xu, Z. Wu, G. Chen, and K. Yokoyama, "Direct identification of structural parameters from dynamic responses with neural networks," Engineering Applications of Artificial Intelligence, vol. 17, no. 8, pp. 931-943, 2004.

[24] Y. Lu and Z. Tu, "A two-level neural network approach for dynamic FE model updating including damping," Journal of Sound and Vibration, vol. 275, no. 3-5, pp. 931-952, 2004.

[25] Q. Chen, Y. W. Chan, and K. Worden, "Structural fault diagnosis and isolation using neural networks based on response-only data," Computers \& Structures, vol. 81, no. 22-23, pp. 2165-2172, 2003.

[26] L. Fryba, Vibration of Solids and Structure under Moving Loads, Thomas Telford Publishing, London, UK, 1999.

[27] G. R. Liu and X. Han, Computational Inverse Techniques in Nondestructive Evaluation, CRC Press, Boca Raton, Fla, USA, 2003.

[28] S. Haykin, Neural Networks: A Comprehensive Foundation, Prentice Hall, 2nd edition, 1998.

[29] Z. Yi and X. Boling, "Orthogonal method for training neural networks," Journal of Nanjing University, vol. 37, no. 1, pp. 7278, 2003.

[30] M. T. Hagan, H. B. Demuth, M. H. Beale, and O. D. Jesús, Neural Network Design, PWS, Boston, Mass, USA, 1996.

[31] J. Hu, Study of load identification and damage detection based on artificial neural networks [M.S. thesis], Zhejiang University, Hangzhou, China, 2005.

[32] D. H. Wu and R. D. Zhao, "Research on the method of load identification for concrete bridge based on neural network," China Railway Science, vol. 23, no. 1, pp. 25-28, 2002. 


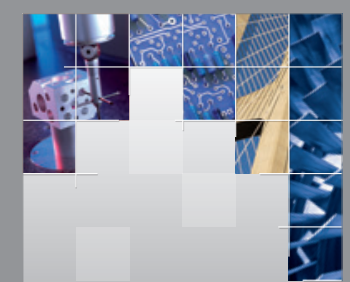

\section{Enfincering}
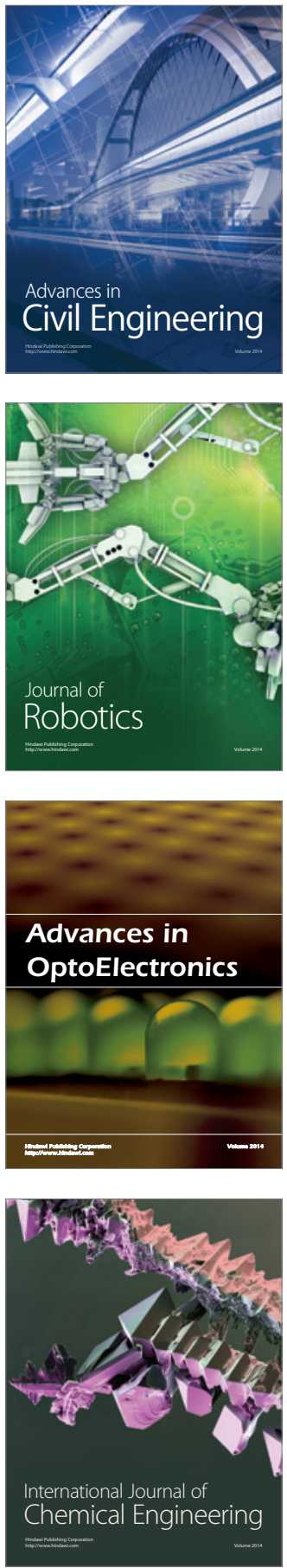

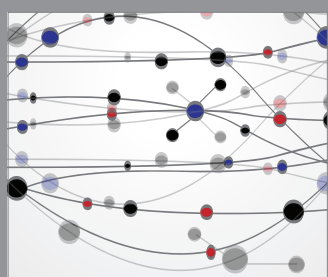

The Scientific World Journal

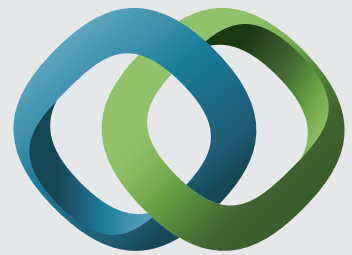

\section{Hindawi}

Submit your manuscripts at

http://www.hindawi.com
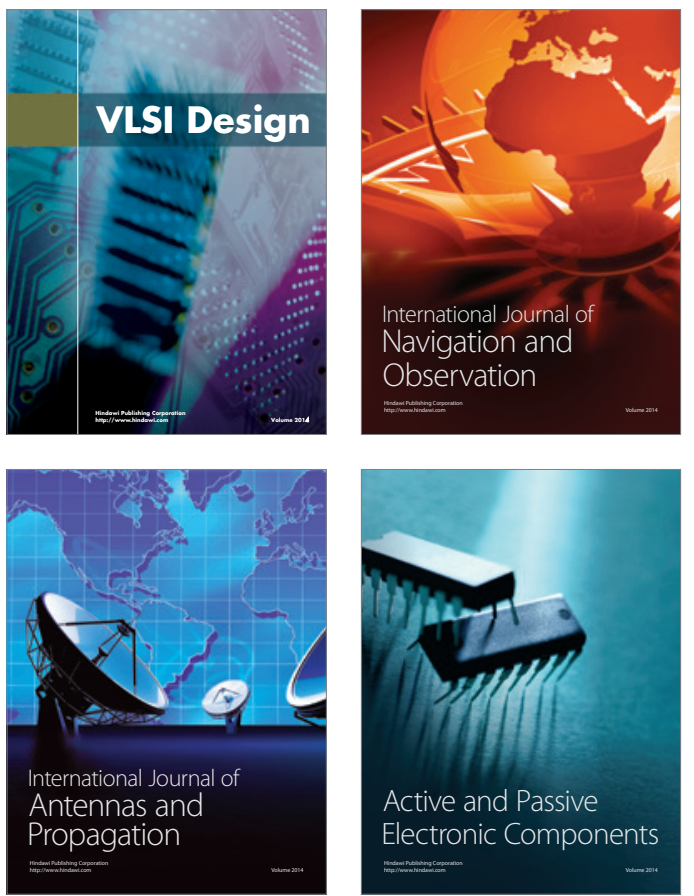
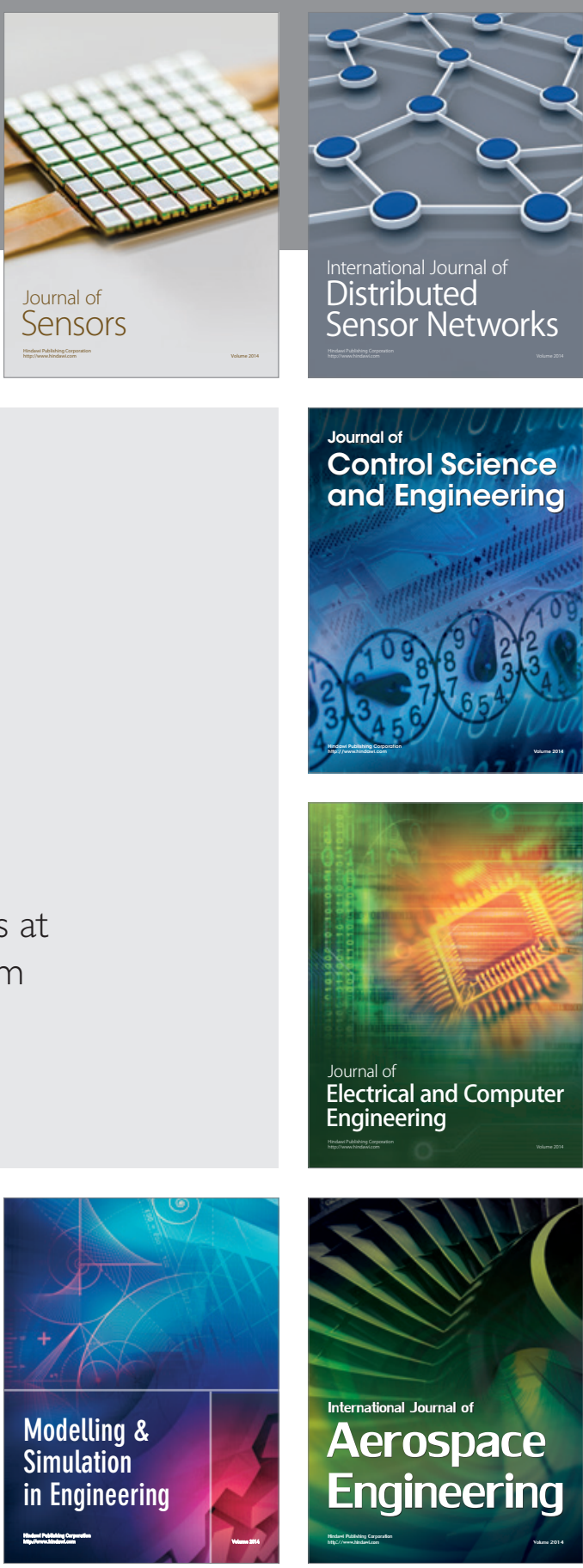

International Journal of

Distributed

Sensor Networks

Journal of

Control Science

and Engineering
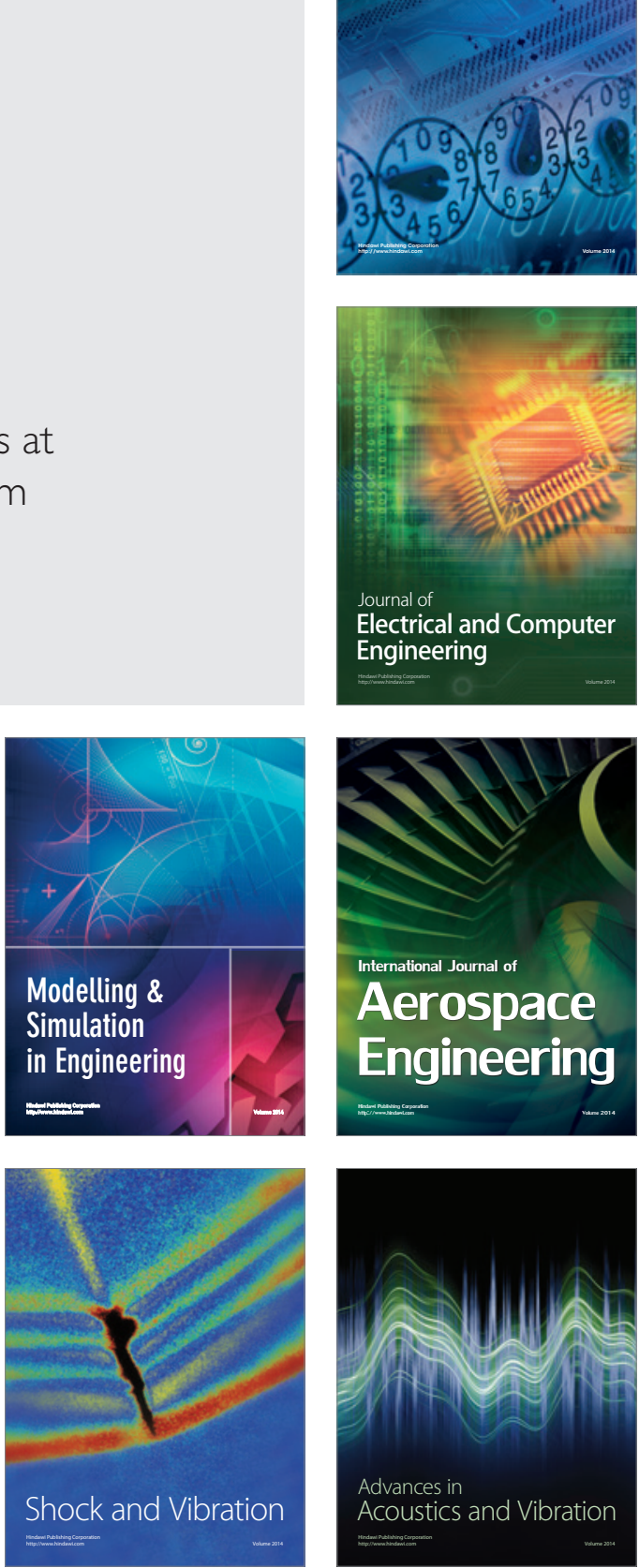